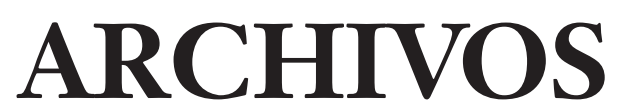

de historia del movimiento obrero y la izquierda

\title{
ENTREVISTA
}

\section{Historia intelectual y marxismo: Una conversación con Elías J. Palti}

\author{
Santiago M. Roggerone
}

Universidad Nacional de Quilmes - CONICET

santiagoroggerone@gmail.com

Elías J. Palti es uno de los mayores referentes de la historia intelectual en América Latina. Es Doctor en Historia por la Universidad de California en Berkeley y se desempeña como Investigador Principal del CONICET con sede de trabajo en el Centro de Historia Intelectual, dependencia de la Universidad Nacional de Quilmes de la que actualmente es director. Ejerce la docencia, asimismo, tanto en esta última Universidad como en la Universidad de Buenos Aires. Entre sus numerosas publicaciones, destacan los libros Giro lingüístico e historia intelectual (1998), La nación como problema (2003), El tiempo de la política (2007), ¿Las ideas fuera de lugar? (2015) y Una arqueología de lo politico (2018).

En 2020 se cumplieron quince años de la aparición de Verdades y saberes del marxismo. Reacciones de una tradición politica ante su "crisis", trabajo en el que, desde un punto de vista histórico-intelectual y apelando a un extenso recorrido a través del pensamiento político contemporáneo, se indagaba en lo que por entonces parecía ser una crisis definitiva. Con la excusa de esta efeméride, conversamos con el autor del libro sobre la más amplia y problemática relación existente entre historia intelectual y marxismo. 
En 2020 se cumplieron quince años de la publicación original de Verdades y saberes del marxismo, libro que recientemente también ha sido traducido al francés. Sería interesante iniciar esta conversación situando el trabajo en el contexto más amplio de tu obra. ¿Qué lugar ocupa en ella y cómo se relaciona con el resto de tu producción?

Te agradezco el haberme recordado que ya pasaron quince años. No me había percatado. Pero bueno, el paso del tiempo es inevitable.

Como seguramente sabrás, mis trabajos están más enfocados en el siglo XIX, algo del XVIII también, sobre todo en América Latina y un poco en Europa. Básicamente lo que hago es apelar a la metodología de la historia intelectual para analizar distintos temas y periodos. Lo que me propuse en este libro es la posibilidad de explorar cómo aplicar esas mismas herramientas conceptuales, concebidas para el estudio de la historia, al análisis del pensamiento contemporáneo. Me interesaba, sobre todo, analizar y enfocarme en la situación actual del pensamiento marxista porque creía que eso me ofrecía la posibilidad de detenerme a observar un fenómeno peculiar que había estudiado ya para otros períodos. Me parecía que éste era un campo particularmente apto para analizar cómo es que se produce en determinado momento lo que podemos llamar una crisis de inteligibilidad. Se trata de situaciones sumamente peculiares, extraordinarias, que no se dan muchas veces en la historia, ni en la historia intelectual, en particular.

Hay una anécdota, una historia judía que cuenta Albert Hirschman, que me parece que puede servir para explicar un poco esta idea. Un día el rabino de Varsovia llama a sus feligreses y les dice que había tenido una visión: el rabino de Cracovia había muerto. Todo el mundo quedó asombrado por los poderes visionarios de su rabino. Otro día, sin embargo, algunos miembros del gueto de Varsovia van a Cracovia y descubren que, en realidad, el rabino de Cracovia vivía -andaba medio mal, pero estaba vivo-. Entonces, cuando vuelven, le cuentan al resto de los judíos de Varsovia lo que habian visto, y, claro, empezaron las murmuraciones. Frente a esto, los más fieles seguidores del rabino de Varsovia dicen: "Bueno, está bien, se habrá equivocado en los detalles pero, de todas formas, qué visión la suya, ¿no?”. Claro, ellos podian alegar que, si bien no había visto lo que había pasado, había hecho algo todavía más increíble: vio lo que iba a pasar -y, es cierto, en algún momento el rabino de Cracovia iba a morirse-.

Lo que trata de ilustrar Hirschman con esta historia es esa capacidad de los sujetos de racionalizar la realidad y asimilarla a las propias creencias. Uno siempre puede adecuar la realidad a sus categorias. El pensamiento siempre logra dar cuenta de la realidad porque si hay algo que no parece encajar dentro de nuestros esquemas, simplemente lo 
descartamos o aparece llanamente como algo invisible, que no forma parte de la realidad; cuanto mucho, un mero accidente sin relevancia.

El punto es que, en algún momento surge, de todos modos, la sensación de que habría algo en la realidad que no se deja asimilar a nuestras categorias, algo que desafia nuestros marcos conceptuales. Sin embargo, explicar cómo esto se produce no es algo sencillo, ni tampoco es frecuente que ocurra, en la medida en que la realidad es algo que nosotros comprendemos siempre a partir de nuestras propias categorias. La pregunta es cómo un dato de la realidad puede revelarse a sus propias condiciones de posibilidad (todo "dato" presupone una grilla teórica que lo constituya como tal).

Entonces, ¿cómo es que surge el sentimiento de que nuestros modos de comprender el mundo ya no logran dar cuenta de la realidad? En fin, ¿cómo es que los sujetos en determinados momentos se ven confrontados a lo que Nietzsche llama experiencias abismales, esto es, una situación en la que, por un lado, no logramos entender la realidad a partir de nuestros presupuestos, que ellos ya no resultan efectivos, pero, por otro lado, tampoco encontramos otros marcos conceptuales que sí lo puedan hacer? Aquí retomo una expresión de Alain Badiou, quien habla justamente del marxismo contemporáneo como un espacio ya inhabitable pero que tampoco puede ser traspasado. Eso es lo que denomina permanecer en la inmanencia de la crisis, y creo que es la mejor metáfora para dar cuenta del tipo de sensaciones experimentadas cuando ocurre una crisis de inteligibilidad. Entiendo que estos fenómenos son particularmente interesantes porque nos dicen mucho respecto de una determinada situación histórica. Lo que me propuse hacer en este libro es una suerte de lectura sintomática: ¿qué nos dicen tales fenómenos de una cierta época que, en este caso, es la nuestra?

¿Qué papel ha jugado el libro en el planeamiento y concreción de tus trabajos posteriores? Mejor dicho, ¿qué irradiaciones produjo hacia el resto de tu obra? Pienso aqui, sobre todo, en Una arqueología de lo político, libro reciente publicado originalmente en inglés. ¿Cómo y bajo qué supuestos se vinculan ambos proyectos?

Me parecía, básicamente, que esto que se llama crisis del marxismo en realidad sería una expresión local de un fenómeno mucho más general que es el que en verdad me interesaba: la quiebra de la política, o, más precisamente, de lo político, a fines del siglo XX. Lo que busqué en Una arqueología de lo político fue ir más atrás en el tiempo y rastrear cómo fue que se produjo ese fenómeno, cómo se llegó a él. Lo que terminé descubriendo entonces es que el campo de lo político no es, en realidad, una entidad eterna, algo que existió siempre, sino que tuvo 
un origen. Fue en el siglo XVII que el mismo apareció, marcando un quiebre histórico fundamental. Lo que me propuse analizar es cuáles fueron las condiciones que dieron lugar a la emergencia de este campo de lo político, cuál es su estructura, y cómo ella se fue alterando a lo largo del tiempo. Esto me llevó a analizar, a su vez, cuáles fueron, en cada caso, los distintos regimenes de ejercicio de poder a los que esas transformaciones de dicho campo dieron lugar, y, finalmente, cómo es que se va a producir la dislocación del mismo.

Lo que señalo en Una arqueología de lo politico son los distintos umbrales que se van atravesando. Hay aquí un debate implícito con Koselleck, quien habla del Sattelzeit, el período umbral que va de 1750 a 1850, cuando, a su entender, nace la modernidad. Esto da lugar, sin embargo, a un esquema dicotómico, a la oposición entre tradición-modernidad. En este esquema de Koselleck no habria lugar para la posible existencia de rupturas conceptuales, tanto antes como después del Sattelzeit. Lo que traté de demostrar en este otro libro es que hubo una ruptura conceptual, igual o más importante aún que la que él analiza, que se dio dos siglos antes, en torno al siglo XVII, que es justamente cuando nace este campo de lo político, y esto se relaciona con la quiebra del universo teológico, con el fenómeno de la secularización.

Lo que hago, entonces, es analizar cómo es que este campo de lo político se desprende a partir de una bifurcación que se da en el interior del universo teológico. Esto supone un replanteamiento de esa otra reconfiguración histórico-conceptual que analiza Koselleck, el Sattelzeit, cuando, como él dice, surge toda una serie de categorias nuevas, se produce la sustantivización de una serie de términos con mayúscula, como los de Historia, Nación, etc. En realidad, según muestro, todas esas categorías no son nada más que nombres que vienen a ocupar el lugar dejado vacante por la quiebra de Dios, que vienen a llenar el vacío dejado por la muerte de Dios.

De alguna forma el Sattelzeit va a ser una respuesta a la crisis que se dio dos siglos antes. Ahora, lo que a su vez se produce en el siglo $\mathrm{XX}$-y acá llegamos al libro sobre el marxismo- es un nuevo quiebre que también Koselleck pierde de vista. En el siglo XX el Sattelzeit ya no existe más. Esto tiene que ver con la crisis de las concepciones evolucionistas teleológicas de la historia, propias de las filosofias de la historia del siglo XIX. Entonces, en el siglo XX, aparece un régimen de saber distinto al surgido con el Sattelzeit. A diferencia de lo que ocurría en el pensamiento evolucionista-teleológico del siglo precedente, los sistemas ya no van a ser percibidos como conteniendo un principio de desarrollo inmanente; se pasa a un régimen de saber que va a estar tensionado por la oposición entre, por un lado, sistemas autorregulados, que sólo 
tienden a la reproducción de su equilibrio interno, su homeóstasis y, por el otro, la subjetividad trascendental o acción intencional subjetiva.

Lo que cambia es que esos sistemas ya no van a ser concebidos como poseyendo un principio de autotrascendencia, de autotransformación, sino que sólo tienden a reproducir su lógica inherente. El cambio, la contingencia, por lo tanto, sería algo que les viene desde afuera, desde un ámbito de subjetividad trascendental. Todo el pensamiento del siglo $\mathrm{XX}$ va a estar atravesado por esa oposición entre estructuras y sujetos, estructuralismo y fenomenología. Y eso se expresa en el ámbito de lo político.

La quiebra de las concepciones evolucionistas teleológicas da lugar entonces a un énfasis en la instancia subjetiva. Ahora lo que se va a colocar en el centro de la reflexión ya no es el automatismo histórico, sino el accionar subjetivo. Esto se expresa de distintas formas en todo el pensamiento, pero creo que una buena síntesis es lo que sucede en el pensamiento de izquierda, en el pensamiento marxista, donde es ahora en el sujeto que se va a creer encontrar ese reservorio de un potencial emancipador en busca de redención. Es eso lo que se expresa, por ejemplo, en el lamento de los freudomarxistas, la Escuela de Frankfurt, cuando se habla de la crisis del sujeto. En El hombre unidimensional, Marcuse dice que la gran crisis que se da en los 60 tiene que ver con lo que él define como la colonización sistémica de los impulsos libidinales, la invasión por parte de las determinaciones sistémica del plano más profundo de la subjetividad -la libido, el deseo-. En Deleuze, en El Anti-Edipo, el ámbito que escapa a la lógica sistémica y que de alguna forma resiste a ella, se identifica con el estadio pre-edípico. En Jameson se trataría de ese residuo de naturaleza incontaminado por el sistema y que él cree encontrar su expresión en el Tercer Mundo. En el marxismo inglés esto se puede rastrear en la idea de experiencia, que es un concepto también de matriz fenomenológica -el concepto de Erlebnis-. La experiencia a la que apelan autores como E.P. Thompson o Raymond Williams es un ámbito de realidad simbólica previa a lo ideológico, que sería la expresión sistémica de las formas de conciencia. Más allá de esas formas atrapadas por lo ideológico, existiría un ámbito de conciencia subjetiva más profundo que nos pone en contacto inmediato con la realidad, que no se encuentra ya mediada o atrapada por el prisma deformante de lo ideológico, y que eventualmente nos permitiría romper con éste y acceder a nuestro verdadero ser como sujetos. Es una variante de lo que Derrida, ya en el último cuarto de siglo, denuncia como la metafisica de la presencia: la idea de un acceso inmediato a la realidad que se coloca por fuera de todo sistema y que, en última instancia, donde se cree encontrar alojado ese potencial que puede desestabilizar 
y eventualmente llevar a dislocar los sistemas (que, como dijimos, ya no se los percibe como poseyendo ningún principio de autotrascendencia).

Esta oposición que atraviesa todo el pensamiento del siglo XX, se expresa, en el marxismo, en su transformación del marxismo clásico al leninismo. Es entonces también que puede surgir finalmente una teoría política marxista. La quiebra de estas concepciones evolucionistas es lo que abre el campo para el pensamiento de la política, o, más precisamente, de lo político. El marxismo del siglo XX va a participar, pues, de estos cambios histórico-conceptuales más generales que se dan de conjunto en el pensamiento occidental. Es por eso que para entender cómo se fue reconfigurando el pensamiento marxista hay que inscribirlo en el marco de esos cambios conceptuales y políticos más amplios. De alguna forma, entonces, Una arqueología de lo politico le da el marco al fenómeno más particular que analizo en Verdades y saberes.

Volviendo a Verdades y saberes del marxismo -es decir, ya no estrictamente en su relación con Una arqueología de lo político-, querría preguntarte cómo surgió la iniciativa-algo mencionaste al comienzo-de analizar la situación contemporánea de la tradición desde un punto de vista histórico-intelectual (o, mejor, desde el punto de vista de lo que vos entendés por historia intelectual). ¿Por qué considerabas que era pertinente atender a la crisis del marxismo -caracterizada como una derrota política y un marasmo conceptual- en tanto fenómeno que daba cuenta de una situación histórica y filosófica más general?

Esto tendria que ver, de alguna forma, con mi trayectoria militante anterior. En mi época militante yo era una suerte de propagandista: aquel que se dedicaba a hablarle a los compañeros hasta convencerlos (o no). Me destacaba también a la hora de debatir a cierto nivel más teórico con aquellos que se nos oponian. ¿Por qué era un buen propagandista? Porque tenía algo que no era muy común dentro de estos grupos de los que participaba. Cuando discutía con alguien, no trataba de refutar lo que el otro decía mostrándole qué es lo que yo veía mal o por qué estaba en contra, por qué no compartía sus ideas. Tenía cierta capacidad para ponerme en la cabeza del otro y, de alguna forma, desmontar la lógica de su propio argumento, ver cuáles eran las inconsistencias de su mismo planteo. No importaba si yo estaba de acuerdo o no -eso era un problema mío, no del otro-. Lo que trataba de demostrarle era cuáles eran los problemas en su propio argumento.

Esta cierta capacidad innata de poder meterme en la cabeza del otro, de poder seguir su propia lógica, y detectar cuáles eran sus núcleos problemáticos, fue lo que me llevó a volcarme después a la historia intelectual. Existía ahí, sin embargo, un punto ciego: tratar de hacer esto 
mismo con el propio pensamiento marxista, entender la lógica de las distintas corrientes en él hoy presentes, reconstruir de alguna forma cómo es que funciona la estructura del argumento de estas diferentes vertientes que existen en el interior del mismo, y detectar, eventualmente, cuáles son los núcleos problemáticos que subyacen a esos diversos planteos.

Cuando presenté el libro, uno de los que estuvo entre los presentadores fue Ernesto Laclau, quien estuvo muy amable, elogió mucho el libro, aunque me dijo que esperaba todavia un segundo trabajo en el que yo manifestara qué opinaba. Le dije que no, que no iba a haber un segundo libro, y le di el ejemplo de Maquiavelo en las Historias florentinas, que es citado por Skinner. En las Historias florentinas, Maquiavelo dice que no hay que contratar a ejércitos de mercenarios porque estos terminan volviéndose contra la propia ciudad que los contrató. Skinner dice entonces que él no se va a poner a discutir con Maquiavelo si hay que pagarle o no a los mercenarios, que lo que trata de entender es qué fue lo que lo llevó a éste a decir lo que dijo y, en definitiva, qué nos dice eso de una época, de una cultura, de un mundo.

Uno de los autores que estudié en el libro fue justamente Laclau. Y entiendo que eso le resultara algo incómodo. No porque discuta con él, sino todo lo contrario. Él seguramente esperaba que me pusiera a debatir sus ideas, no sé, si las cadenas equivalenciales de las que habla son de tal o cual modo, etc. Es muy dificil discutir, en cambio, con alguien como yo, a quien, en realidad, no le interesa debatir nada de lo que a él le interesaba discutir, y que, simplemente, te pone en el lugar de un objeto y trata de analizar qué es lo que te llevó a afirmar lo que estás afirmando -más allá de si acuerdo o no con lo que el otro dice-. Es decir, tomar sus dichos como objetes de análisis para tratar de entender a partir de ellos qué nos dicen acerca de una determinada época histórica, cómo nos ayudan a entender una determinada situación, sin pretender dar respuestas; más sencillamente, entender cuáles son las preguntas a las cuales hoy nos estamos confrontando. Creo que eso es una tarea mucho más compleja y difícil, y, en el fondo, más interesante, que la de pretender dictaminar al respecto, entender qué es lo que está hoy en disputa, cuáles los dilemas a los que nos confrontamos.

La siguiente pregunta, de hecho, está relacionada con esto. Siempre me llamó la atención que en las primeras páginas del libro lo demarcaras de otros trabajos tuyos por tratarse de un proyecto de indole más personal, y señalaras, además, que con él habías buscado saldar algunas deudas pendientes. Seria sumamente interesante si pudieras referirte aunque sea de manera breve -algo ya dijiste-a estas deudas. ¿En qué medida y hasta qué punto tu propia experiencia militante constituyó un factor de 
peso a la hora de concebir la obra? En esta suerte de ajuste de cuentas que anunciabas, ¿qué papel jugó tu paso por la academia norteamericana $y$, particularmente -para evocar el titulo de otro libro de tu autoría-, el encuentro con el giro lingüístico y toda una serie de teorias o filosofias que de alguna manera implicaban un punto de vista diverso respecto a lo que habia sido tu experiencia militante previa?

En realidad, las herramientas no son del giro lingüístico sino de la historia intelectual. Creo que las herramientas más propias de la historia intelectual me ofrecieron, en general, una perspectiva novedosa para abordar el pensamiento marxista, distinta a las que normalmente se emplea. Básicamente, lo que me brindaban era la posibilidad de tomar distancia crítica respecto al objeto, no ponerme a discutir con estos autores y terminar colocándome en un mismo plano con ellos, y poder pensar, abrir un espacio para el análisis.

En el fondo, esto es lo que se llama una lectura sintomática. El analista no se pone a discutir con el paciente si está bien o mal lo que está diciendo; lo que trata de ver es cuáles fueron los mecanismos que llevaron a ese sujeto a decir lo que dijo y qué es lo que sus dichos denotan. La historia intelectual me permitía esto, sobre todo-volviendo a la pregunta original- trazar un panorama de cuáles fueron las distintas reacciones que se produjeron frente a lo que se ha percibido como una crisis del marxismo; más precisamente, cómo reaccionaron ciertas corrientes de pensamiento ante una situación que se experimenta como una crisis de inteligibilidad.

De ahi viene la idea de verdades y saberes. En esto, el libro traza dos grandes momentos: uno tiene que ver con el marxismo del siglo XX, y otro que sería ya el del marxismo de fines del siglo XX. En el marxismo del siglo XX había dos grandes vertientes, las cuales analizo en los dos primeros capítulos del libro. Por un lado está la corriente anglosajona de Perry Anderson, Fredric Jameson, etc., que, frente a la percepción de la inviabilidad del proyecto político marxista, va a seguir intentando reivindicar el marxismo al menos como un saber. Ellos van a encontrar la pervivencia del marxismo, su validez, en el hecho de que -como pensamiento- sería el único marco teórico capaz de dar cuenta de su propia crisis, y eso es lo que le daría superioridad teórica. Esto es lo que los lleva a enfocarse en lo que se conoce como marxismo de cátedra: tratar de construir la saga de los aportes conceptuales del marxismo en la política y construir la genealogía de los grandes pensadores marxistas.

A esto opongo otra corriente. Nahuel Moreno me sirve como ejemplo para dar cuenta de la reivindicación de la dimensión más estrictamente política que teórica del marxismo, una dimensión militante con la que se piensa al mismo como una herramienta para transformar la realidad 
antes que para pensarla -la famosa tesis once sobre Feuerbach-. Y ahí trato de ver cómo cambia el marxismo del siglo XX en este plano, ya no de la teoría sino de la política militante. Esto me permite analizar otra de las posibles reacciones frente a la crisis del marxismo, cómo se experimenta la misma en el plano no académico sino de la práctica militante.

Particularmente relevante aquí me parecía la reinterpretación que hace Moreno de la famosa fórmula marxista de la alternativa socialismo o barbarie, cómo Trotski relee la misma, etc. Ya en el siglo XX, esta fórmula, para Moreno, cobra un sentido muy distinto al que tuvo en Marx. Para Marx, la alternativa era socialismo o barbarie, pero entre ambos términos había una asimetria, porque, en última instancia -todavía en el marco de las filosofias evolucionistas del siglo XIX-, estaba convencido de que de las dos sólo la primera podía ser una alternativa última y final. La barbarie es simplemente un obstáculo frente al avance del socialismo que no puede convertirse en una alternativa última por una sencilla razón: la burguesía necesita al proletariado pero éste no necesita a aquélla, entonces la primera puede derrotar al segundo pero no puede nunca destruirlo porque es de donde se alimenta. Esto no ocurre así con la alternativa socialista. El capitalismo puede derrotar al proletariado una y mil veces pero tarde o temprano éste se va a volver a levantar y va a terminar destruyendo al capitalismo, y una vez que eso suceda éste ya no dejaría de existir, ya no tendría posibilidad de volver a resurgir.

Según Moreno, en el caso de Trotski -que está escribiendo ya en los años 30, en medio de la emergencia del fascismo, el nazismo, etc.-, lo que se plantea es el surgimiento de una nueva forma de barbarie que puede poner fin a la posibilidad misma de la existencia del socialismo como alternativa. Se produce así una simetría entre estos dos principios: el destino último puede ser el socialismo o puede ser la barbarie, una forma de barbarie superior que dé por tierra con toda posibilidad futura de socialismo. Y es ahí, como se ha repetido muchas veces, que la acción política cobra verdaderamente sentido.

Es en el siglo XX cuando nace una teoría política que no había todavía en Marx y el marxismo clásico. En el marco de las teorias evolucionistas de la historia -que es todavía la visión de la historia de Marx- la acción subjetiva tiene un rol subsidiario. Es importante hacer la revolución para no seguir sufriendo, pero el curso histórico no va a cambiar; tarde o temprano el socialismo se va a terminar imponiendo. Sólo cuando aparece la idea de que puede haber una forma poscapitalista que no sea la socialista, una forma que dé por tierra con la posibilidad del socialismo, es que la acción militante cobra otro sentido de urgencia; aparece la sospecha de que, si no hacemos la revolución ahora, quizás no podamos hacerla nunca más. Ya no se trata de una mera cuestión 
de plazos: la acción militante adquiere ahora un sentido sustantivo que tiene que ver con la determinación de los fines últimos de la historia y no simplemente de sus ritmos. Es en este marco, como decía, que surge verdaderamente la subjetividad militante. No quiere decir que no hubiese militancia política antes, pero ésta no tenía aún en su horizonte inmediato la toma revolucionaria del poder. Eso es algo que sólo surge en el siglo XX.

Cambia entonces completamente el escenario: el eje se desplaza del análisis de la lógica del capital a la de la formación del partido, un ejército revolucionario, etc. Y es acá que tiene lugar lo que Goldmann -y esto es un punto central que se desarrolla en el libro- llama visión trágica del mundo. Badiou toma una frase de Mallarmé y dice algo parecido: el siglo XX es el momento en que la política se vuelve tragedia. ¿Cuál es el significado de esta visión trágica del mundo? Goldmann, que estudió el pensamiento jansenista del siglo XVII, retoma la idea de apuesta de Pascal. Nos encontramos en medio del período de la secularización -lo que analizo en Una arqueología de lo politico-, cuando se produce la muerte de Dios. Pascal dice entonces que ya no tenemos ninguna certidumbre de la existencia de Dios, se ha quebrado ya la certeza acerca de la misma, pero que es justamente eso lo que nos obliga a buscarlo de forma permanente. Dios, dice, se nos revela en su propio mutismo, pero para que el mismo funcione debe ser absoluto. ¿Por qué? Porque si Dios se nos revelase en el mundo, si encontráramos algo de validez incondicionada en él, podríamos entonces reconciliarnos con éste (el mundo) y olvidarnos de aquél. Lo que nos obliga a buscar de manera permanente a Dios es justamente la pérdida de sentido del mundo. Esa radical insustancialidad del mundo es lo que nos impide reconciliarnos con él y persistir en su búsqueda, en el afán de dotarle un sentido de trascendencia a un mundo que ha perdido todo sentido trascendente, que se ha vuelto carente de toda sustancia.

De alguna forma, Goldmann expresa esto mismo para el marxismo del siglo XX. Es precisamente la quiebra de la certidumbre teleológica, el que no tengamos ninguna seguridad de que la revolución se vaya a dar de modo ineluctable, lo que nos obliga a perseverar en la lucha por el proyecto marxista. Justamente porque la acción militante cobra el carácter de una apuesta a lo absoluto. Lo que funda la persistencia en la búsqueda del ideal socialista ya no es la certeza de su realización; por el contrario, es la propia incertidumbre la base que empuja a su búsqueda. Este es el sentido trágico que adquiere la política en el siglo XX. Sucede no sólo en el marxismo, pero él es una buena expresión de este nuevo carácter que cobra entonces la acción politica. El siglo XX es, de alguna forma, el siglo de la politica, el momento, como decía Mallarmé, en que la historia se convirtió en política y ésta se volvió tragedia. 
En relación a esto que decías de la impronta subjetiva que de alguna manera cobra el marxismo en el siglo XX, en el libro parecería haber un intento de explorar una secuencia de descomposición que atañería a la divinidad, la historia, el sujeto y el sentido en cuanto tal. En Una arqueología de lo político esta exploración adquiere quizás una fisonomía más inteligible ya que, Koselleck mediante, atendés a tres periodos: la era de la representación, la era de la historia y la era de las formas. ¿Cómo se relaciona aquella exploración inicial de Verdades y saberes del marxismo con esta otra periodización más sistemática? Tomando lo que recién sugerias a partir de Goldmann, ¿de qué modo se vinculan ambas periodizaciones con la hipótesis de la entrada en una escena postrágica?

Esto que mencioné hasta aquí era el marxismo del siglo $\mathrm{XX}$, el que surge como consecuencia de la crisis de las concepciones evolucionistas decimonónicas de la historia. Éste entra en crisis, a su vez, a fines del siglo dando lugar al surgimiento de toda una nueva corriente de pensamiento, que es la que analizo en la segunda mitad del libro (y que constituye su núcleo): lo que Marchart denomina pensamiento posfundacional y yo asocio aquí con el llamado marxismo posestructuralista.

Esto nos devuelve al siglo XX. Había, en realidad, una relación paradójica entre historia y sujeto en el siglo XX. ¿Por qué? Porque, como vimos, es la quiebra de la idea de Historia (con mayúscula) lo que da lugar a la emergencia del sujeto, que permite que la acción subjetiva cobre un carácter sustantivo y ya no meramente subsidiario. La idea de sujeto nace de la quiebra de la idea de Historia en singular, cuyo surgimiento, a comienzos del siglo XIX analizó Koselleck. Pero esta idea más fuerte de Sujeto, que nace de la quiebra de la idea de Historia, al mismo tiempo la presupone; tiene implícita la existencia de un cierto curso unitario que avanza hacia delante, que se orienta hacia un determinado fin, porque, de lo contrario, tampoco la acción subjetiva tendría sentido alguno -es decir, si no hubiera una unidad de sentido que se dirigiese o que marchara hacia algo, si no tuviera un marco de un desarrollo dentro del cual ella cobrara un sentido que la trascendiese, la acción subjetiva se agotaría en sí misma-. En definitiva, la acción militante excluye y presupone a la vez una filosofia de la historia.

Según muestro, la quiebra de la concepción evolucionista teleológica, que en un primer momento dio lugar a la sustantivización o sustancialización de la instancia subjetiva, va a ser también lo que terminará, ya hacia fines de siglo XX, llevando a ésta a su crisis. Nietzsche decía que sin Dios la Verdad no puede ya ser sostenida. De alguna forma, sin Historia tampoco la idea de Sujeto va a poder sostenerse. Para Badiou, lo característico de la situación presente del pensamiento marxista es que todas las instancias subjetivas se encuentran ya destruidas. La idea 
misma de sujeto revela su trasfondo mítico, y, como señala Laclau, los mitos son como esos juegos en donde no se puede decir su nombre -una vez que se los nombra, dejan de funcionar como tales-.

¿Qué es la desustancialización del concepto de historia que se produce en el siglo XX? Si bien la historia no se abandona, se convierte en un concepto genérico, pierde todo contenido positivo. Ya no se puede predicar nada sobre la historia, no se puede decir más que ella es tal cosa o cual cosa, que marcha en tal o cual dirección; la idea misma de que haya leyes de la historia ya no puede sostenerse, aparece como una mera metáfora. Con el sujeto sucede lo mismo. A fines del siglo XX se produce una desustancialización del sujeto, se convierte en un concepto genérico que funciona nada más que como una marca de la contingencia, de la inconsistencia de la historia. Así es que aparecen ideas de la subjetividad como la de multitud en Hardt y Negri, una entidad vacía incapaz ya de encarnar ningún proyecto político determinado. Ninguna misión histórica cuya realización se le pueda encomendar. Nada, en fin, que lo defina salvo su fuerza o impulso genérico para su propia manifestación. La multitud aparece así como una suerte de masa informe de la que puede nacer todo y nada al mismo tiempo. Es parecida, por ejemplo, a la idea de democracia de Lefort, en donde también opera una desustancialización del concepto. La democracia se convierte en un concepto genérico, que se define como una atopología de los valores; es decir, que en ella ya no se puede identificar ningún lugar social particular como la encarnación de una verdad o de un valor.

¿Qué es lo que aparece acá entonces? La introducción de la figura de Derrida en mi libro me parece que es importante, porque creo que -no siendo estrictamente un pensador marxista- él es quizás el que mejor capta qué es lo que queda de todo esto en un contexto de crisis de lo político, donde su campo se ha visto ya dislocado. La idea de justicia en Derrida sintetiza bien lo que entonces surge como producto de la desustancialización de las categorías políticas. Esta sirve, además, para él, como índice del marxismo hoy. En última instancia, la idea de justicia proviene del pensamiento teológico; es un concepto que tiene que ver con el supuesto de la existencia de un orden natural, ciertos principios eternos que fueron establecidos por Dios y que se encuentran inscriptos en la naturaleza misma. Estos principios de justicia son objetivos, independientes de la voluntad del sujeto.

Con la modernidad esto cambia desde el momento en que los sujetos son ahora los que tienen que instituir aquellos valores según los cuales van a presidir su convivencia colectiva. Pero la modernidad no va a poder abandonar completamente la idea tradicional de justicia, de la existencia de ciertos principios objetivos, independientes de la voluntad 
del sujeto, como serian, por ejemplo, los llamados derechos naturales o derechos humanos inherentes.

Lo que se descubre entonces es que los códigos normativos son puramente convencionales, se trata de convenciones humanas. Sin embargo, aún entonces no se puede prescindir de la invocación de una cierta idea de justicia, porque si se aceptara que los códigos son puramente convencionales entonces no habría ninguna obligación de obedecerlos. Hay que suponer que hay en ellos implícito algo del orden de la justicia, que es, en última instancia, de donde esos códigos convencionales toman su fuerza normativa. Es lo que analizo que abre el campo a lo político, este juego de inmanencia y trascendencia. Lo que se plantea entonces, aquello que articula ese campo de lo político, es cómo crear un efecto de trascendencia a partir de la inmanencia, un sentido de justicia a partir del derecho, o un sentido de legitimidad a partir de la legalidad. Cada régimen de ejercicio del poder surgido a partir de entonces no es nada más que un distinto modo de producción de un efecto de trascendencia a partir de la inmanencia-que es, justamente, lo que estudio a lo largo de Una arqueología-.

¿Qué es lo que aparece ahora con la idea de justicia de Derrida? Aparece esta idea desustancializada de la justicia. Ya no se piensa realmente que haya algo más allá de lo dado, sino que lo que existe es la propia invocación a algo más allá de lo dado. La justicia no existe, pero, no obstante, siempre se la puede invocar para impugnar un sistema normativo dado -uno puede decir que algo es legal pero no justo-. La justicia no es, pues, nada más que la marca de la contingencia de todo orden normativo convencional, históricamente constituido. Invocar la justicia es postular la existencia de un más allá del derecho, del orden existente, sin que exista verdaderamente nada más allá. Simplemente indica que esto que existe no es una realidad eterna, universal, fundada en la pura razón o en la naturaleza. En última instancia, la idea de justicia indica la necesidad de seguir postulando la existencia de un más allá de lo dado aún una vez que sabemos que, en realidad, no hay algo más allá.

Esta es la escena postrágica a la que me refiero, que es también la experiencia del desastre de la que habla Blanchot. Se trata de cómo pensar un sentido luego de la quiebra del sentido, la existencia de un más allá aún cuando sabemos que ya no existe algo más allá. Y es a partir de este marco que abordo el pensamiento de estos marxistas posestructuralistas, y el de Badiou en particular. A diferencia del sentido trágico del que hablaba Goldmann respecto de Pascal, éste sería una apuesta de segundo grado. Hay una apuesta, pero ya no es a lo absoluto, como en Pascal. Toda apuesta presupone ya la presencia de un sujeto que apuesta. De lo que se trata ahora es de una apuesta a 
la existencia misma de la apuesta, a un sujeto de la apuesta; es una apuesta a constituirnos a nosotros mismos como sujetos ilusorios de nuestras propias ilusiones del sentido.

Se produce entonces una suerte de pliegue, de torsión del pensamiento sobre sobre sí mismo. Esta es la estructura, la lógica que articula toda esta forma de pensamiento propia de lo que se llama posfundacionalismo. Y es lo que define la dinámica más propia de una escena que es ya postrágica, distinta a cómo funcionaban las cosas en el pensamiento de la política en el siglo XX. Es esa lógica entonces la que me propuse reconstruir; cómo opera el pensamiento de la política en una escena que es ya postrágica.

Ojalá que haya sido claro porque son cuestiones densas, para nada sencillas de explicar. Tampoco es fácil resumir el argumento del libro en unas pocas líneas. El punto que me gustaría que quede al menos claro es que en él intenté estudiar a estas corrientes no como normalmente se lo hace -esto es, quedándose en el plano del propio discurso, reponiendo qué es lo que dice uno u otro- sino tratando de ir más allá, enfocándome en qué es lo que subyace a lo que cada quien plantea.

Cambiando un poco de tema, me parece que justamente una de las apuestas del libro consiste en analizar cómo el marxismo reaccionó a su crisis por medio de la figura de Moreno. Repongo rápidamente tu argumento para ver si lo podés desarrollar a partir del prisma de hoy. A diferencia de los filomandelistas Anderson y Jameson, y en sintonía con los esfuerzos de alguien como Badiou, Moreno habría abogado por salvar la tradición como verdad, cosa que a su vez suponía destruirla como saber. En lo fundamental, según entiendo, lo que distinguiria la operación de salvataje referida llevada a cabo por el dirigente trotskista argentino es su inscripción en una visión trágica del mundo -en Badiou, en cambio, la misma se ajustaría a una visión de indole postrágica, más logicista y formalista que dialéctica, y emparentada con lo que de la mano de Blanchot llamabas, efectivamente, experiencia del desastre-. A esto se podría contraponer-de hecho, se lo hizo-que, más allá de la primacía de lo politico y la determinación subjetivista del marxismo que pudo haber propuesto, Moreno fue un trotskista conservador, una suerte de voluntarista escatológico que creía que la revolución era inminente. Si bien oportunamente replicaste a esto, me gustaría preguntarte cómo hoy, a quince años de la aparición original del libro, analizás el impacto que ocasionó tu lectura.

Me han criticado mucho por tomar la figura de Moreno, como si con ello hubiera querido reivindicarlo. Entre otras cosas, me cuestionaron que yo no habría visto su voluntarismo. En realidad me parece que eso 
no es un punto importante, es más bien algo trivial. En primer lugar, porque el optimismo revolucionario es, en realidad, algo inherente a toda práctica militante. Por otro lado, cabe entender que el mismo respondia a ciertas condiciones históricas: a mediados de siglo XX, y por lo menos hasta fines de los 80 , la revolución parecía algo inminente. No era una idea de Moreno. De hecho, se habian dado revoluciones en todo el mundo entonces; casi la mitad de la población del mundo vivía bajo regímenes socialistas. Sobre todo el impacto de la revolución cubana fue decisivo al respecto. El que se hubiera hecho una revolución socialista a doscientas millas de la primera potencia mundial -y que hubiera sobrevivido- parecía ser una prueba irrefutable de que el socialismo era posible.

De hecho, no sólo lo pensábamos nosotros, los trotskistas; también la CIA lo hacía, y por eso se dedicaba a financiar golpes de Estado. La CIA tenía la idea de que no sólo América Latina, sino también África y Asia, de un momento a otro iban a girar al socialismo -parte del último continente lo había hecho ya-. En fin, no me parece que éste sea el aspecto más interesante de Moreno, ni un rasgo peculiar de él. En el fondo, los que discuten esto es porque pretenden hallar cuál era la línea correcta. Discuten con Moreno como si fueran miembros del comité central del partido y quisieran explicarle cómo debería haber hecho las cosas.

No es eso, ciertamente, lo que me interesa hacer a mí. Lo que me parece más interesante de Moreno es cómo se expresan en él ciertas paradojas implícitas en la propia práctica militante, en el intento de salvar al marxismo ya no meramente como un saber. Para Moreno, y para el trotskismo en general, sería absurdo decir -como decian Jameson o Perry Anderson- que la superioridad del marxismo consiste en su capacidad teórica; afirmar que, aunque no funciona como práctica política, sí lo hace como pensamiento. Es como si un médico dijera que la operación fue un éxito pero que el paciente murió. Si murió, no puede haber sido un éxito. Es como afirmar que la teoría funcionó pero que en la práctica no se pudo hacer nada. Esto no tiene sentido para un militante en la medida en que reivindica al marxismo como una herramienta para transformar la realidad y no meramente para pensarla. Lo que Moreno se propone entonces es salvar el marxismo como herramienta política para transformar la realidad, aún al precio de tener que destruir todo su saber.

¿Pero dónde está el punto ciego? En lo que decía antes: la reformulación de la idea de socialismo o barbarie, la idea de que existe un umbral, un horizonte, un límite más allá del cual el socialismo se volvería ya imposible. Como vimos, es esto lo que da sentido sustantivo al accionar militante. La existencia de ese límite, pues, es algo que, por un lado, es necesario postular, pero que nunca, sin embargo, se puede 
determinar desde el interior del marxismo, porque si aceptáramos que hemos traspasado ese umbral, ya tampoco tendría sentido alguno la acción militante, el pretender seguir siendo marxista o militante revolucionario. Es decir, hay que postularlo sólo como un concepto límite sin nunca poder definirlo.

Este es el punto ciego propio de esta línea de pensamiento. Y esto se relaciona, en última instancia, con la crítica de Moreno al mandelismo. Aunque Mandel nunca termine de decirlo así, dado que él pretende seguir participando de la tradición marxista, su idea del neocapitalismo supone que hemos entrado ya en una fase dentro de la cual la revolución socialista habria dejado de ser una alternativa, que hemos cruzado ese umbral. De ahí surgen entonces estos intentos de querer salvar la tradición marxista ya no como proyecto político, como práctica política, sino como saber. Pero, para Moreno, esto no tiene sentido. Si fuera así, si el socialismo hubiera dejado de ser una alternativa factible, si hubiese realmente surgido un régimen de producción poscapitalista, que no sea el socialista, ya no tendría sentido seguir siendo marxistas. De allí, en fin, que este límite deba ser postulado como tal, sin nunca poder definirlo, en tanto que marxistas.

Lo que me interesaba analizar en esta primera parte del libro, pues, era este contraste entre dos formas de confrontar el tipo de crisis que enfrentó el marxismo en el siglo XX, por un lado desde la teoría y por otro desde la práctica militante. En la segunda mitad, atiendo a lo que sucede cuando ya toda esa lógica política propia del siglo XX también se quiebra y da lugar a otra, que es la que se expresa en la otra serie de pensadores que analizo -y en la que Badiou ocupa un lugar central, pero también tomo a otras figuras, como Laclau, Zizek, Rancière, etc.; en fin, toda esta franja de pensamiento posestructuralista que constituye, en realidad, el núcleo del libro.

Quería preguntarte también por la tematización que proponés de la última crisis del marxismo como una crisis terminal. ¿Qué tendría de particular esa crisis que haría de ella, justamente, una crisis última y final? ¿Cómo esto entra a jugar o dialogar con una lectura como la de Sazbón, la cual obviamente citás y que supone que la experiencia de la crisis sería algo intrinseco al marxismo en cuanto tal? Me interesaba ver si podias retomar algo de este diagnóstico y traerlo hacia el presente, en donde toda una producción marxista, o al menos marxistizante, podría llegar a hacer las veces de un indice de que algo de la tradición, en tanto saber -y no ya en tanto verdad, quizás-, persiste.

Hay una serie de pensadores -sobre todo los marxistas posestructuralistas- que dicen que esto que estamos experimentando ahora no 
tendría nada que ver con lo que normalmente se llamó, desde siempre, crisis del marxismo. Como señala Sazbón, toda crisis tiene implícita su resolución. La crisis, etimológicamente, es un término médico que designa un momento de inflexión a partir del cual se produce la cura o la muerte. Contemporáneamente surge lo que se llama una crisología, según la cual las crisis tendrian también dos tipos de resolución posibles: una crisis se resuelve intrasistémicamente, mediante los mismos mecanismos inmanentes a la tradición dada, como la marxista, o lleva a abandonarla y a adherir a alguna otra; es decir, en este caso la recomposición sólo se podría lograr a partir de otro marco teórico distinto.

Una crisis terminal como de la que hablo es justamente la que no se inscribe dentro de ninguno de los dos conceptos de crisis; no se puede resolver en el interior de los propios marcos pero tampoco da lugar a su abandono. Decir "dejo estas ideas porque ahora abracé otras ideas distintas" no es propiamente una crisis terminal, ni conlleva una crisis de inteligibildad. Ésta se da cuando algo ya no se sigue sosteniendo pero no hay otra cosa que sí se pueda sostener. Una crisis del sentido nos está hablando de un contexto histórico conceptual ya muy distinto, peculiar, donde lo que estamos confrontando es algo que tiene que ver con el orden de una experiencia en la que se están planteando un conjunto de problemas nuevos, extraños hasta ahora para nosotros, y frente a los cuales ya no encontramos una solución posible, que no encajan con nuestras propias categorias pero tampoco con ninguna de las disponibles.

Lo que busqué analizar en este libro es cuáles son los problemas que se están planteando hoy que no parecen tener una posible solución, y que tienen que ver básicamente con la quiebra de ese juego de inmanencia y trascendencia que fue el que abrió el campo de lo político en el siglo XVII. Hoy ese juego de inmanencia y trascendencia se habria vuelto superfluo. Con el proceso general de desustancialización de los conceptos políticos (lo que llamo la reversión del Sattelzeit), dicho juego ya no puede seguir funcionando.

Antes que nada, lo que me importa es cómo pensar qué tipo de política surge una vez que este campo de lo político se ha desarticulado, que ese juego de inmanencia y trascendencia se ha quebrado. Esa sería la gran pregunta que subyace a todos los debates teóricos que hoy se plantean, y recorren centralmente el pensamiento marxista posestructuralista. Lo que me interesa es ver no qué dice cada quien sino cuál es el núcleo en torno del que giran hoy los debates, más allá de las distintas posturas al respecto. El problema que se plantea hoy, en última instancia, es cómo pensar un nuevo horizonte de la política ya desprendido del campo de lo político; cuál es la lógica que articula este nuevo campo de la política donde eso que surgió en el siglo XVII 
ya no existe más; y cómo puede generarse un nuevo pensamiento de la emancipación en un marco donde todas las categorías en función de las cuales el mismo se articulaba -la serie de oposiciones que habian articulado el campo de lo político- perdieron ya su sentido. Todo intento de escapar de esta problemática, en realidad no hace más que rehuirla, sin alcanzar así a calibrar la verdadera dimensión del desafio al que nos enfrentamos. Se termina cayendo, en última instancia, en alguna forma de ingenuidad política y epistemológica, siendo que todo intento de resolución muestra rápidamente sus inconsistencias y, en definitiva, la trivialidad de su planteo.

Para ir terminando me gustaria hacerte unas preguntas de indole más estrictamente historiográfica. Verdades y saberes del marxismo apareció mientras se desarrollaba el llamado affaire del Barco. Interviniste intensamente en el mismo, planteando entre otras cosas que lo que te interesaba llevar a cabo tenía las características de una arqueología de la subjetividad militante. Considerando esto pero también lo que señalabas sobre tu enfoque -es decir, que es deconstructivo en el sentido de poner en práctica una lectura sintomática de determinados textos-, queria preguntarte si entendés que es plausible y útil llevar a cabo otro tipo de ejercicios historiográficos para abordar el marxismo. En otras palabras, ¿cuáles deberian ser los lineamientos fundamentales de un programa historiográfico sobre los marxismos, sus legados, sus herencias, etc.?

Esta lectura, si se quiere deconstruccionista o sintomática, busca oponerse a lo que en historia de las ciencias se llama lecturas internas, las cuales explican, por ejemplo, la historia de la física como la de los progresivos hallazgos y como un proceso acumulativo de saber donde nuevos descubrimientos se van adicionando, y van así lográndose teorías cada vez más consistentes. La historia interna sería entonces la historia de un proceso progresivo de acumulación de conocimientos. En este libro trato de romper con este esquema, el limitarse a hacer una lectura interna del marxismo como un proceso progresivo de aumento de saber, la historia de los grandes aportes, los grandes hitos, los jalones del pensamiento marxista, etc. Más que en una historia acumulativa y lineal, me enfoco en una historia de los problemas, de cómo se fue reconfigurando el pensamiento marxista.

El punto fundamental, que aquella perspectiva pierde de vista, es que este pensamiento se va a reconfigurar históricamente no a partir de sus propias problemáticas inherentes. La tradición de pensamiento marxista se va a ir reconfigurando a partir de su inscripción en campos histórico-conceptuales más amplios, y que no obedecen a su propia dinámica intrínseca. Como vimos, los cambios que se producen en el 
pensamiento marxista del siglo XX tienen que ver con la quiebra de las concepciones evolucionistas teleológicas del siglo XIX, y eso no es algo que él determinó sino que le vino dado, y que establece un nuevo universo histórico-conceptual al cual también dicho pensamiento tendrá que adecuarse, un nuevo terreno dentro del cual éste habrá de inscribirse.

Todo el pensamiento marxista del siglo XX, y los cambios que se produjeron en su interior, no resultan inteligibles si no comprendemos cómo se reconfiguró el campo de saber más general en Occidente, reconfiguración que tiene que ver con los cambios que se dieron no sólo en la filosofía y la teoría política sino también en las ciencias naturales. También en la biología, por ejemplo, se rompe con las concepciones evolucionistas de la noción de organismo. Los conceptos de organismo o evolución que tenían en mente Marx o Hegel no eran los mismos que surgen en el siglo XX, a partir de la llamada teoría sintética o el neodarwinismo. En fin, todas las categorias se van a reformular. Es una mutación epistémica general que entonces se produjo.

En efecto, las herramientas conceptuales fundamentales, el utillaje mental a partir del cual los sujetos pueden pensar la realidad entonces mutaron, y, por ende, también los modos en que el marxismo piensa lo hicieron en forma consonante a estos cambios más generales en los regimenes de saber, lo que Foucault llamará epistemes. Es por eso que no creo que se pueda hacer una historia del marxismo que no tome en cuenta esos cambios históricos conceptuales más generales. Una historia interna nunca puede dar cuenta de la propia naturaleza y dinámica de estas transformaciones que se dieron en el interior de esa tradición de pensamiento.

En conexión con esto, y para finalizar, ¿cómo hay que pensar -si creés que vale la pena hacerlo, claro- la dimensión de la recepción o de la asimilación y reinterpretación de ideas, autores, corrientes o teorías referenciadas en diferentes versiones del marxismo que ocurrieron y se desarrollaron en Argentina, América Latina o las periferias en general? Quizás más específicamente aún, ¿en qué debería consistir, tanto en términos de objetivos como de procedimientos epistemológicos, una historia intelectual o-por qué no- conceptual del marxismo en la Argentina?

En primer lugar, esa distinción entre centro y periferia hay que matizarla. ¿Qué es el centro y qué es la periferia? Normalmente se parte de una visión abstracta y genérica respecto de cuáles son los centros y cuáles las periferias. Habría que desagregar estas categorias genéricas, y observar, concretamente, cómo funcionó una determinada problemática en cada momento y lugar particular. En todo caso, el trazado de genealogias de pensamiento resulta poco relevante. Saber de dónde vino una 
cierta idea o cómo llegó nos dice aún muy poco de cómo se resignificó y a qué función sirvió en un momento y lugar dados.

En última instancia, el hablar de recepción me genera ya problemas porque suele plantearse mediante categorias que por lo general tienen una carga metafísica, conlleva una suerte de reificación de las ideas. Como decía Wittgenstein, no existen ideas sino usos. Analizar los usos requiere trascender el plano puro de las ideas para enfocarse en la dimensión pragmática de los discursos, en el plano retórico de los mismos. Las ideas son siempre abstractas y genéricas, por definición. Ellas no guardan las huellas de los cambios producidos por los desplazamientos contextuales. Para tomar el caso de la recepción del marxismo en Argentina, si nos enfocamos en el plano de las ideas, no vamos a encontrar nada específico o peculiar al contexto local, ninguna idea propia que no se pueda encontrar en cualquier otro lugar del mundo. Para descubrir aquello que particulariza los usos de los discursos en un contexto particular hay que trascender el plano de las ideas y enfocarse en la dimensión retórica, en el conjunto de relaciones pragmáticas de los discursos; no en qué se dijo, sino en cómo se dijo, quién lo dijo, a quién, dónde, cuándo. Lo que se altera con los cambios contextuales no son las ideas, sino su sentido. Las mismas ideas, aún cuando su formulación sea exactamente igual, alteran su sentido en función de cuál es ese conjunto de relaciones pragmáticas específicas en que se produjo su enunciación. Creo que esta perspectiva se encuentra ya, de algún modo, implícita en al menos algunos de los textos clásicos del marxismo. Hablar sin más de la recepción del pensamiento marxista conlleva, en definitiva, su reducción a una mera corriente de pensamiento, cuyos aportes en tanto que tales habria que tratar de rescatar, perdiendo así de vista todo aquello que hizo, y, según creo, aún hace del mismo, algo más que eso, que resiste su reducción a un mero saber. 